\title{
Correlates of Internet Addiction among Adolescents
}

\author{
Alfred D. Waldo \\ Philippine Mental Health Association, Baguio-Benguet Chapter, Baguio City 2600, Philippines \\ Email: waldogz_way@yahoo.com \\ Received 1 September 2014; revised 28 September 2014; accepted 21 October 2014 \\ Copyright (C) 2014 by author and Scientific Research Publishing Inc. \\ This work is licensed under the Creative Commons Attribution International License (CC BY). \\ http://creativecommons.org/licenses/by/4.0/

(c) (i) Open Access

\begin{abstract}
Internet addiction is a broad concept. Despite inconclusive or inconsistent definition for this disorder, usage of the internet is growing rapidly each year especially among adolescents, making it imperative to look into factors that can be correlated to it. The study provided description on adolescent internet addiction and examined significant differences in terms of gender, type of school and online behaviors. Further, the relationship of adolescent internet addiction to spiritual intelligence, psychological wellbeing and social desirability was explored. Questionnaires were used in the data collection; findings suggest that adolescents are frequent online users and that there are significant differences in terms of gender, school type, and online behaviors; social desirability had a strong positive relationship with adolescent internet addiction.
\end{abstract}

\section{Keywords}

Adolescents, Internet Addiction, Spiritual Intelligence, Psychological Wellbeing, Social Desirability

\section{Introduction}

Internet addiction is a broad concept. To date, there is neither a conclusive nor a consistent definition for this disorder. Despite efforts made to reach one uniform definition, and inclusion in the Diagnostic and Statistical Manual 5 (DSM5), the authoritative guidebook for the diagnoses of psychiatric disorders by the American Psychiatric Association, difficulty establishing a coherent picture for this disorder is often encountered by researchers and clinicians (Block, 2008). Young (1996) defined internet addiction as an impulse-control disorder like pathological disorders that does not involve an intoxicant. Shapira (as cited in Bastani, 2008) stated that this may be another form of obsessive-compulsive disorder. Despite these inconsistencies, most researchers believe that the definition can be explained by online behaviors such excessive use to certain applications online, unregulated/pathological/problematic hours online (Frangos, Frangos, \& Sotiropoulos, 2011). 
In this study, as the researcher's target is to provide description of internet addiction among adolescents the term Adolescent Internet Addiction (AIA) was coined as it particularly describes the characteristics and online behaviors of adolescents. Online behaviors are described as the purpose of internet use and internet hours consumed by adolescents. Further, adolescents and high school students are used synonymously.

Previous studies perceived the internet as having an overall negative effect on their daily lives and a break in the individual's psychological wellbeing. These studies defined wellbeing in the concept of mental illness and distress such loneliness and depression (Whang, Lee, \& Chang, 2003); current mental health treatments and behavioral difficulties (Mannell, Zuzanek, \& Aronson, 2013); impulsivity, sensation and novelty-seeking, social isolation (Young \& Roger, 1998) and sometimes enhanced levels of aggression (Chou, Condron, \& Belland, 2005). Similarly, Oktuğ's (2010) study reported wellbeing as a state compromised such as failure to manage time, missed sleep, missed meals, and so on picturing similar patterns and norms of other addictions.

In this study, however, psychological wellbeing is defined in the concept of positive mental health. The definition of Carol Ryff's multi-dimensional construct of psychological wellbeing was used. According to Ryff the overall well-being is the interconnectedness of six distinct facets: (1) self-acceptance or feeling positive towards the self and accepting one's strengths as well as weaknesses; (2) positive relations with others or having close, warm, and supportive relationships and feeling connected to others; (3) personal growth entails openness to new experiences and a commitment to development and learning; (4) purpose in life involves feeling committed to valued goals and believing that life is meaningful and worthwhile; (5) environmental mastery entails feelings of personal competence and efficacy and confidence in one's ability to interact successfully with the environment; and (6) autonomy is a sense of self-determination and independence and a willingness to stand up for one's own ideas and beliefs despite external pressures (Negovan, 2010).

Meanwhile, another element of positive mental health is spiritual intelligence. Gardner presented this as the ninth intelligence (Sisk, 2008). Spiritual intelligence is one of the several types of intelligence that can be developed independently and contributes to psychological well being and overall healthy human development (Perez, 2012). According to studies (as cited in Azadeh, Fatemeh, \& Rouhparvar, 2012), spiritual intelligence has a positive relationship with public health and stress reduction (Ali Mirzaei, 2008), better quality of life and life satisfaction, prospectiveness (Mirshamsi, 2009), high self-esteem (Hyde, 2004), mental health (Moalemi, Raqibi, Salari Dargi, 2010), happiness (Bagheri, 2010), hope to recovery and prospectiveness (Flannelly, 2001), the ability to overcome pain and agony (Madhujain and Trema, 2006), reduction of depression (Bahrami Dashtaki, Alizadeh, Ghobari Bonab, 2006), and a negative relationship with adolescent identity confusion (Javadzadeh Shashani, 2011).

Since well-developed spiritual intelligence could be associated with positive consequences for the individual, it will be useful and necessary to identify the variables that increase the probability of its reduction. Therefore, spiritual intelligence was included in this study as a variable with the assumption that its higher levels of AIA would decrease spiritual intelligence.

On the other hand, it is established that addicted individuals to substance abuse or other forms of addictions were found to have higher levels social desirability. Crowne \& Marlowe (1983) defined social desirability as the tendency to give overly positive self-descriptions in an attempt to appear overly moral, honorable, and virtuous yet denying undesirable traits (e.g. sexual or drug-related behaviors). This response strategy is used to be accepted by social peers due to the consistent social norms and expectations (Fleming, 2012). Hence, in this study social desirability is used as a response trial to be associated with AIA in order to assess if adolescents deny internet related problems and online behaviors.

Erikson viewed adolescence as a pivotal period. He stated that the main psychosocial task for an adolescent is finding an optimal balance between self-knowledge and identity confusion (Mazalin \& Moore, 2004). He also emphasized peer relations in the development of a social sense of self. According to him, adolescents' sense of psychological well-being is a feeling of being "at home" in one's body and a sense of knowing where one is going is achieved through identity achievement. Identity achievement reflects the epitome of adolescent mental health, adjustment, and self-esteem, and is a predictor of positive social and psychological outcomes, such as positive psychological well-being (Waterman, 2007 as cited in Mazalin \& Moore, 2004).

Carl Jung was a pioneer in asserting that all human problems are spiritual. He believed that human beings are not only psychosexual and psychosocial but they are also psycho-spiritual. Jung stated that psychological problems are essentially spiritual or religious. He believed that psychoneurosis is the suffering of the soul which has not discovered its meaning leading to stagnation, or psychic sterility. Hence, he suggested that healing is not 
possible without spiritual awakening or addressing issues related to spiritual distress (Itliong, 2006).

Both of these concepts served as the framework for understanding the present study. Traditionally, little is understood about the Filipino adolescence psychological wellbeing and spiritual intelligence. AIA is even more debated and its influence to the Filipino adolescent wellbeing and spiritual intelligence has not been fully examined. Thus, by associating these factors this study may narrow the gap, acknowledging the possibility that each factor can serve both positively and negatively dependently of the other. Therefore, the following objectives were determined:

1. The degree of Internet addiction, Spiritual intelligence, Psychological wellbeing, and Social desirability of adolescents.

2. The significant differences of Adolescent Internet Addiction in terms of gender, type of institution, and online behaviors.

3. The relationship of Adolescent Internet Addiction to Spiritual Intelligence, Psychological wellbeing and social desirability.

\section{Methods and Procedures}

\subsection{Study Design and Population}

The research is a quantitative study which utilized a correlational design. The study was conducted in Baguio City. Participants in this study were high-school students from various secondary schools (public and private schools) from freshmen to senior high school enrolled during 2013-2014 academic school year.

With the increase in computers and the universal application of the internet has brought great convenience, adolescents in Baguio City use the internet for academic and recreational purposes. In order to ascertain how much time respondents spent on-line, respondents were asked to provide a best estimate of the number of hours per day on online activities. It is important to note that these estimates were based upon the number of hours spent for pleasure/entertainment or personal interest (e.g., personal e-mail, scanning news groups, playing interactive games) and even academic or research/information seeking related purposes. Table 1 presents a summary of the profile and online behaviors of the respondents by frequencies and percentages.

The study applied multi-stage sampling in the target recruitment. The researcher determined the sampling frame by obtaining the list of secondary schools from the department of education. The first stage in sampling was determining the school participants. 8 schools were selected to participate in the study in an equal ration (1:1) so 4 schools from the private and 4 public schools. Selected schools were contacted via telephone calls and personal visits to ask permission from the school administrators for the participation of their students in the study. Some schools declined to participate in the study prompting the researcher to reselect other school participants. The researcher obtained the number of enrollees in the 8 schools who agreed to participate in the study. A total of 5417 freshmen to senior high school students were obtained. The second stage of sampling was

Table 1. Profile and online behaviors of the respondents.

\begin{tabular}{|c|c|c|c|}
\hline Variables & & Response frequencies & Percentage \\
\hline \multirow{2}{*}{ Gender } & Male & 525 & 49.6 \\
\hline & Female & 534 & 50.4 \\
\hline \multirow{2}{*}{ Type of Institution } & Private Schools & 383 & 36.2 \\
\hline & Public Schools & 676 & 63.8 \\
\hline \multirow{4}{*}{$\begin{array}{l}\text { Most common use of } \\
\text { Internet }\end{array}$} & Research/academics & 331 & 31.3 \\
\hline & Social networking/chatting & 289 & 27.3 \\
\hline & Online gaming/gambling & 313 & 29.6 \\
\hline & Surfing/other purposes & 126 & 11.9 \\
\hline \multirow{4}{*}{$\begin{array}{l}\text { Hours of internert } \\
\text { use per day }\end{array}$} & 1 - 2 hrs. & 475 & 44.9 \\
\hline & 3 - 4 hrs. & 294 & 27.8 \\
\hline & 5 - 6 hrs. & 170 & 16.1 \\
\hline & $7+$ hrs. & 120 & 11.3 \\
\hline
\end{tabular}


determining the sample size of the study. The sample size was determined using the 2006 Researchers Advisors sample size table. Based on the table, the appropriate sample size for 5417 is 1176 . By percentage allocation the sample size distributed to each school participants. The third stage in sampling was determining the student participants. Cluster sampling was employed in the selection of student participants. For each year level, depending on the type of institution, there are 2 to 4 classroom per year level. In each classroom student population would range from 30 - 60 students. By randomly selecting the section representative of each year level, all students meeting the inclusion criteria was invited to participate in the study.

\subsection{Measures and Data Collection}

Young's Internet Addiction Test (IAT). This was adapted to evaluate the respondents' level of internet addiction. It consists of 20 questions wherein each item is scored using a five-point Likert scale. It covers the degree to which internet use affect daily routine, social life, productivity, sleeping pattern, and feeling. The instrument has exhibited good psychometric properties in previous researches. The reliability for this questionnaire is 0.899 in Cronbach's alpha the higher the score the greater the level of internet addiction (Pui, 2006).

The Spiritual Intelligence Self-Report Inventory (SISRI-24). This is a 24-item self report measure of spiritual intelligence widely used for academic, educational, or research purposes. The tool exhibits a reliability coefficient of $\alpha=.94$ by Cronbach's alpha. Item responses ranged on a 5-point Likert scale from 0 ("not at all true of me") to 4 ("completely true of me"), with higher responses representing higher levels of spiritual intelligence. A total spiritual intelligence score can be calculated by summing across all subscales (King \& DeCicco, 2008).

Carol Ryff's Scales of Psychological Wellbeing (SPWB). The SPWB scales have been found to demonstrate good construct validity with other well-being measures in young adults, middle-aged adults (Abbott, Ploubidis, Huppert, Kuh, Wadsworth, \& Croudace, 2006). The tool has also been used in major studies and in addition has been cited in more than 400 studies. The response format for all items comprised six ordered categories labeled from "disagree strongly" to "agree strongly". Twenty PWB items were positively worded and 22 negatively worded. Prior to analysis, negatively worded items were reverse scored so that high values indicated well-being. The internal consistency coefficients were quite high between 0.86 and 0.93 and the test-retest reliability coefficients for a subsample of the participants over a six week period were also high 0.81 - 0.88 (Springer \& Hauser, 2011).

Marlowe \& Crowne's Social Desirability Scale. This is a 33-item self-report questionnaire, with TrueFalse format for responding to the items. The MCSDS is intended to capture a person's "need for social approval", which is the extent to which a person seeks approval from others and avoids disapproval (Johnson \& Fendrich, 2013) this tool is a public domain instrument, making it cost effective for users. Crowne and Marlowe's (1960) studies revealed an internal consistency coefficient of .88, and one month test-retest correlation of .89. Respondents who answer in the affirmative/negative to the socially desirable/undesirable questions have a higher need for social approval and are more likely to respond to research questions in a socially desirable manner (Tatman, Swogger, Love, \& Cook, 2013).

As the tools were initially designed for use in the United States, some statements referenced cultural phenomena were not relevant to the Filipino culture. This was revealed after the Content Validation of the questionnaires. A panel of experts consisting of four professionals agreed to evaluate the content validity of the tool. Recommendations from panel of experts led to further revisions. The test questionnaires were pretested to 33 high school students with similar characteristics as the actual respondents. The reliability of the tools was determined using a 2 weeks test-retest method resulting to the following correlation coefficients of .83, .72, .74, and .70 for Internet Addiction Test, Spiritual Intelligence Self-Report Inventory, Scales of Psychological Wellbeing, and Social Desirability Scale respectively. All necessary modifications, deleted items, results of the reliability and validity were reported back to the panel of tests experts.

After receiving approval and obtaining consent from the school administrators the questionnaires were personally administered by the researcher. All questionnaires were distributed to willing participants at their respective classrooms at a predetermined time. The nature of the study was masked by not presenting the title of the study in the questionnaires. Teachers left the classrooms during the data gathering time. All ethical considerations were explained for those who participated in the study. On-site retrieval of the questionnaires was done after 45 minutes. 


\subsection{Treatment}

The Statistical Package for Social Sciences (SPSS) version 21.0 was used. In presenting results for all analyses, the $p$-value of 0.05 was used as the decision rule wherein $p$-value below 0.05 indicates rejecting null hypothesis while $p$-value above 0.05 indicates acceptance of the null hypothesis.

\section{Results}

Over 7 weeks, period of data collection, out of the distributed 1176 questionnaires only 1059 (90.05\% response rate) were deemed valid and complete which were subjected for analysis. Respondents had a mean age of 16.45.

Table 2 presents the descriptive statistics of the study. It can be noted that although adolescents have good psychological well-being and acceptable levels of spiritual intelligence, adolescents appear socially desirable at an average level and are frequent online users.

As seen in the Table 3, all the variables have significant differences on adolescent internet addiction. Males are found to be more addicted to the internet than females, and students form private schools are more addicted to the internet than those from public schools. Student's utilizing the internet mainly for surfing/other purposes are more addicted to the internet. At the same time, internet addiction increases as hours of internet use increases.

On the other hand, presented in Table 4 is the relationship of all AIA with SQ, the dimensions of wellbeing

Table 2. The descriptive statistics and interpretation.

\begin{tabular}{cccc}
\hline Variables & Mean & Interpretation \\
\hline Adolescent Internet Addiction & & 39.12 & Frequent Online Users \\
Spiritual Intelligence & & 39.44 & Average SQ \\
& Autonomy Dimension & 3.61 & Good \\
& Environmental Mastery & 3.59 & Good \\
Psychological Wellbeing & Personal Growth & 4.08 & Good \\
& Positive Relations & 3.91 & Good \\
Social Desirability & Self-Acceptance & 3.88 & Good \\
\hline
\end{tabular}

Table 3. The difference of AIA in terms of gender, type of school, and online behaviors.

\begin{tabular}{|c|c|c|c|c|}
\hline \multicolumn{2}{|c|}{ Variables } & Mean & $\mathrm{f} / \mathrm{t}$ statistic & $\rho$ \\
\hline \multirow{3}{*}{ Gender } & Male & 40.004 & \multirow{3}{*}{2.350} & \multirow{3}{*}{$0.019^{*}$} \\
\hline & & & & \\
\hline & Female & 38.251 & & \\
\hline \multirow{3}{*}{ Type of school } & Private & 41.674 & \multirow{3}{*}{5.175} & \multirow{3}{*}{$0.000^{*}$} \\
\hline & & & & \\
\hline & Public & 37.673 & & \\
\hline \multirow{4}{*}{ Purpose } & Research/Academics & 35.323 & \multirow{4}{*}{16.508} & \multirow{4}{*}{$0.000^{*}$} \\
\hline & Social Networking/Chatting & 40.571 & & \\
\hline & Gaming/Gambling & 40.840 & & \\
\hline & Others/Surfing & 41.492 & & \\
\hline \multirow[t]{4}{*}{ Behaviors } & $1-3 \mathrm{hrs}$ & 35.697 & \multirow{4}{*}{37.247} & \multirow{4}{*}{$0.000^{*}$} \\
\hline & $3-5$ hrs & 39.364 & & \\
\hline & $5-7$ hrs & 42.865 & & \\
\hline & $7+\mathrm{hrs}$ & 46.767 & & \\
\hline
\end{tabular}

Note: ${ }^{*}$ Sig at $\alpha=.05$. 
Table 4. The Pearson correlation of AIA, SQ, PWB and SDS.

\begin{tabular}{|c|c|c|c|c|}
\hline Variables & & Mean & $\mathrm{r}$ & $\rho$ \\
\hline Adolescent Internet Addiction & & 39.12 & - & - \\
\hline Spiritual Intelligence & \multirow{3}{*}{ Autonomy Dimension } & 39.44 & $.111^{* *}$ & .000 \\
\hline \multirow{7}{*}{ Psychological Wellbeing } & & \multirow{2}{*}{3.61} & 0.32 & .301 \\
\hline & & & -.022 & .473 \\
\hline & Environmental Mastery & 3.59 & -.022 & .465 \\
\hline & Personal Growth & 4.08 & .11 & .714 \\
\hline & Positive Relations & 3.91 & -.046 & .136 \\
\hline & Purpose in Life & 3.88 & -.017 & .591 \\
\hline & Self-Acceptance & 3.72 & & \\
\hline Social Desirability & & 17.68 & $.065^{*}$ & 0.34 \\
\hline
\end{tabular}

Note: ${ }^{*}$ Sig $=.05 .{ }^{* *}$ Sig $=.01$.

and social desirability. Although the dimensions environmental mastery, personal growth, purpose in life and self-acceptance did not reach standard significant levels they were consistently presenting to have inverse relationship with AIA. This only suggests that as addiction to internet increases these dimensions in wellbeing decreases. Meanwhile, the dimensions autonomy and positive relations have positive relationship with AIA but not significant. Also another significant finding is the positive relationship between spiritual intelligence and social desirability to AIA.

\section{Discussions}

\subsection{Degree of AIA, Level of SQ, Degree of PWB, and SDS}

Majority of adolescents are frequent online users. Indeed, Internet addiction is a global mental health problem (Chou \& Hsiao, 2000). Epidemiological studies showed that the international prevalence rate of adolescent internet addiction ranged from $0.9 \%$ to $38 \%$ (Xu et al., 2012). Alarmingly, in this study $24.7 \%$ met the criteria for internet addiction. Erikson viewed that the main task for an adolescent is finding an optimal balance between self-knowledge and identity confusion. Thus, by guiding and teaching students on healthy coping strategies to life-related situations such as stress, sadness, and depression we may help them we may be able to help students explore possible alternatives in finding their identity and roles in productive ways. Nurses are crucial in the development of the identity of adolescents, therefore promoting healthy lifestyles, emphasizing proper coping on psychosocial issues, recognizing programs and existing services for adolescents in the prevention, management, and treatment of AIA must also come from the health sector.

The Spiritual intelligence of adolescents is average. This is because Filipino adolescent's link their spiritual intelligence to their spiritual experiences (Perez, 2012); Filipino adolescents may have imbibed a strong adherence to the social teachings of the bible (Austria, 2009); they cultivate an optimistic attitude that contributes to emotional balance and the capacity to survive (Wang, n.d); and have Filipinos ability to accept reality (including failure and defeat) in terms of God's will (Hetherington, 2011). Carl Jung emphasized the ability of humans to draw on spiritual resources in problem-solving and dealing with the issues of the concept of life and values. Perhaps this may contribute to the understanding that adolescents seek divine interventions in solving their problems.

In terms of the adolescence psychological well-being, Erickson stated that identity formation is a complex process and can be associated with different psychosocial outcomes depending upon the socio-cultural milieu. Therefore, cultural differences essentially accounts for the variations in some of the dimensions. In this study, adolescents have Good/maintained psychological well being with above $50 \%$ of the overall respondents on the six dimensions of psychological well being. With below $5 \%$ of the overall respondents some scored poor and slightly low in the six dimensions. As the six dimensions of psychological wellbeing works hand in hand in the development of adaptive human functioning and positive life experiences (Springer \& Hauser, 2011). Our ultimate goal is to create a balance among the dimensions. Equally important to the prevention of ill-health is 
building good health and wellbeing. Research suggests that high wellbeing has preventative effects on the development of mental health problems over time (Pudrovska, Springer, \& Hauser, 2005). Perhaps enhancement programs may be designed specifically considering the areas in which the dimensions that are low and devoting time and resources may help students to thrive psychologically, physically, socially, and academically.

In terms of the degree on social desirability, evidence that social desirability is a personality trait is that it appears to be genuinely related to emotional stability and conscientiousness (Tatman, Swogger, Love, \& Cook, 2013). In this study, adolescents have average social desirability. For the Filipino youth, these personality traits may be described as norms and values instilled by their parents and according to the expectations of society (Hetherington, 2011). Perhaps, this positively stated description was selected by the some adolescence in the sample as their description to self-presentation.

\subsection{Difference of AIA in Terms of Gender, Type of School, and Online Behaviors}

According to Pallanti, Bernardi and Quercioli (2006) the average age for students who are with internet addiction is $16.67 \pm 1.85$ (as cited in Qin, 2011). It means that, adolescent who are addicted to internet are within the age range of 14 years old to 18 years old which matches the age range used in this study. Following Erickson's identity development, Marcia developed identity statuses involving movement from less mature (diffusion, foreclosure) to more mature (moratorium, achievement) identity statuses over the adolescent age range. According to Marcia, 15 - 19-year-olds seek vehicle for exploration of the world which might characterize their lifestyles in preparation for adult life. In a study conducted by Hasanzadeh, Beydokhti, and Zadeh (2012) they have found out that at least $50 \%$ of participants remain diffused or foreclosed at the end of their secondary school studies. They were able to conclude that internet use facilitate and retard psychosocial development among high school students particularly at the moratorium stage (19 years old/early adolescents). Needless to say, the current study is thus still a salient one, the higher use of internet the higher diffusion of the identity of teens.

As expected, male adolescents were found to have higher levels of internet addiction as than their female counterpart. This provides support to the findings of Mazalin \& Moore (2004), Chen \& Fu (2009), Sato (2009), Beutel (2011), and Kennedy, Wellman, and Klement (2003) utilizing teenage population for the comparison on gender difference on internet addiction. In this study, adolescent male's use the internet as a social mean or as a ground for interpersonal relations. Most studies in this field usually indicate female that seek out close friendships and prefer anonymous communications (Young, 1996). This unexpected finding seems to support Chou, Condron, and Belland (2005) finding that internet use is a substitute for real-life social interaction. Interventions, treatment programs, preventive strategies may be designed specifically considering the areas in which the two genders are different and similar.

Griffith's (1998) found significant associations of internet addiction with higher social status, ease of use, availability, and accessibility. Undeniably, adolescents from private school institutions have higher social status, have multimedia resources (latest and newest gadgets such as i-pad's, smart phones, tablets, etc. that have internet connection features), and may be proficient to various technical features of software applications, computers and networks as compared to those in public schools. Apart from this, some private schools have WiFi connections available in their campus grounds. Computer laboratories have access to internet. Therefore, it is no leap to predict that students from private schools are more vulnerable AIA than students from the public schools given the dispositions and social norms of private schools. Perhaps school administrators may look into this concern and re-examine school policies concerning internet connection use among campuses.

It is reductive that in problems encountered by adolescents overlap and interacts in complex ways. Abstaining from Net use is seldom an option (Young, 2004), as adolescents use this tool for their academic pursuits dependency was observed from different campuses. Adolescents prefer socializing online more than in person due to the faceless community of the internet (Razieh, Ghasempoor, Ajdari, \& Sadeghigooghari, 2012), Sexual pursuits on the internet can carried out because it can easily be accessed, anonymous, and a medically safe way to satisfy one's biological drive and psychological needs (Chou, Condron, \& Belland, 2005), Particular activities online for reinforces satisfaction to the needs (Griffiths, 1998, 2000) are among the identified reasons for the online behaviors among adolescents. Furthermore, in terms of time consumption the study collaborates with previous findings (Young, 1996, 1998; Chen \& Fu, 2009; Chou \& Hsiao, 2000; Beutel, 2011; Frangos, Frangos, \& Sotiropoulos, 2011) that the higher the consumption the higher the level of addiction. Clearly, remedial guidance is 
necessary for the dependent adolescent. It might be helpful for parents set consistent rule on internet hours of use at home. In school settings, perhaps school rules and regulations on ethical and proper use of mobile phones, iPads, and technology in general with internet connection may be implemented. In order to understand AIA it is suggested that helping professionals, parents, concerned adults must also look into particular applications or use that the adolescents engage in and identify presenting problems with this use.

\subsection{The Relationship of AIA to SQ, PWB, and SD}

The strong positive correlation between internet addiction and social desirability may possibly be explained as a mechanism to avoid self-criticism. Denial enables adolescents to continue engaging in internet usage in spite of obvious negative consequences; it is also a way to protect themselves from seeing or feeling things that are unpleasant. Owing to denial, the impact of one's internet usage is seldom fully appreciated until the consequences become serious (Chang \& Hung, 2008).

In studies of students indicating excessive use of internet and mental health (Kraut et al., 1998; Chou \& Hsiao, 2000; Chen \& Peng, 2008; Douglas et al., 2008; Ko et al., 2005, 2012; Eastin, 2005; Azadeh et al., 2012; Engelberg \& Sjoberg, 2004) results indicated that the level of depression, stress, suicide intention, hyperactivity, fear, social fear, aggression, violence and antisocial behaviors occur more in addicted students. Chang \& Hung (2008) stated that the internet is used by addicts as a medium for avoiding and dealing with these underlying problems. However, as claimed by Chang \& Hung (2008) the mental health problems and psychological problems are the core issues in internet addiction use itself. It is still controversial, however, to propose this relationship between psychological well-being and internet addiction. The question then becomes "is the internet a delivery medium or is it a causal factor?” Given the discussions above, we can safely assume that by giving adolescents a purpose in life, a sense of direction, increasing their self acceptance and exposing them to an environment where they can adjust, master their skills, foster personal growth and adjustments we will be able to prevent internet addiction. Likewise, various activities that promote independence and provide group acceptance might be indicative of overcoming internet dependency/addiction among identified adolescents.

As we come to better understand internet addiction, we are less likely to consider it a single phenomenon but rather an intersection of multiple physical, psychological, technological and possibly spiritual phenomena. Although it is suggestive that SQ is not too far-fetched with AIA the relationship may represent a different condition along a spectrum of related disorders to psycho-spiritual maladjustment. Rahmani \& Lavasani (2011) suggested that internet addicts have accepted the internet as a way to create spiritual change in them and similarly, adjustment in negative moods. It seems that this way, although harmful, is the shortest and most available way for them. Although this is suggestive it might be useful to draw upon it as an example, in order to seek other possible factors.

\section{Recommendations}

Awareness to the extent of this problem should be pursued to a wide range of audiences. In line with previous findings, besides proper diagnosing and treatment effective management and prevention is necessary. School administrators may perhaps add information services to the "student guidebook" instead of just placing rules and regulations. As there is no space for remedial guidance and preventive actions in the "student guidebook" wellness programs, extracurricular activities, and volunteer works stating the objectives of such programs and how it can benefit the youth and their well-being may be included. Lastly, future research may employ different methods of inquiry particularly on a causal perspective and pursue the study to a wider scale of population and different target groups.

\section{References}

Abbott, R. A., Ploubidis, G. B., Huppert, F. A., Kuh, D., Wadsworth, M. E., \& Croudace, T. J. (2006). Psychometric Evaluation and Predictive Validity of Ryff's Psychological Well-Being Items in a UK Birth Cohort Sample of Women. Health and Quality of Life Outcomes, 4, 76.

Austria, A. T. (2009). Perceived Riskiness and Frequency of Participation in Risk Behaviors among Selected Filipino Adolescent Offenders in Baguio City. Unpublished Master’s Thesis, Bonifacio St. Baguio City: Saint Louis University.

Azadeh, F., Fatemeh, S., \& Rouhparvar, A. (2012). The Predictive Role of Loneliness and Internet Addiction and the Moderating Role of Field of Study and Gender in Students. www.primejournal.org 
Bastani, S. (2008). Gender Division in Computer and Internet Application: Investigation of the Students of Tehran Universities. Women Studies, 5, 45-64.

Beutel, M. E., et al. (2011). Regular and Problematic Leisure-Time Internet Use in the Community: Results from a German Population-Based Survey. Cyberpsychology, Behavior, and Social Networking, 14, 291-296.

http://dx.doi.org/10.1089/cyber.2010.0199

Block, J. J. (2008). Issues for the DSM-V: Internet Addiction. The American Journal of Psychiatry, 165, 306-307. http://dx.doi.org/10.1176/appi.ajp.2007.07101556

Chang, J. \& Hung, C. (2008). Problematic Internet Use. http://iacapap.org/wp-content/uploads/H.6-internet-addiction-072012.pdf

Chen, S., \& Fu, Y. (2009). Internet Uses and Academic Achievement: Gender Differences in Early Adolescence. http://www.thefreelibrary.com

Chen, Y., \& Peng, S. (2008). University Students’ Internet Use and Its Relationships with Academic Performance, Interpersonal Relationships, Psychosocial Adjustment, and Self-Evaluation. CyberPsychology and Behavior, 11, 467-469. http://dx.doi.org/10.1089/cpb.2007.0128

Chou, C., \& Hsiao, M. C. (2000). Internet Addiction, Usage, Gratification, and Pleasure Experience: The Taiwan College Students' Case. Computers \& Education, 35, 65-80. http://dx.doi.org/10.1016/S0360-1315(00)00019-1

Chou, C., Condron, L., \& Belland, J. C. (2005). A Review of the Research on Internet Addiction. Educational Psychology Review, 17, 363-388. http://dx.doi.org/10.1007/s10648-005-8138-1

Crowne, D., \& Marlowe, D. (1983). A New Scale of Social Desirability Independent of Psychopathology. www.garfield.library.upenn.edu/classics1983/A1983QJ72000001.pdf

Eastin, M. S. (2005). Teen Internet Use: Relating Social Perceptions and Cognitive Models to Behavior. www.ebscohost.com

Engelberg, E., \& Sjoberg, L. (2004). Internet Use, Social Skills, and Adjustment. http://www.dynam-it.com/lennart/pdf/eng\%20och\%20sj\%20cyber\%20psych\%202004.pdf

Fleming, P. (2012). Social Desirability, Not What it Seems: A Review of the Implications for Self-Reports. http://tijepa.webs.com/Vol\%2011.1/A2_V11_TIJEPA.pdf

Frangos, C. C., Frangos, C. C., \& Sotiropoulos, I. (2011). Problematic Internet Use among Greek University Students: An Ordinal Logistic Regression with Risk Factors' Negative Psychological Beliefs, Pornographic Sites and Online Games. CyberPsychology, Behavior and Social Networking: http://www.liebertonline.com

Griffiths, M. D. (2000). Does Internet and Computer “Addiction” Exist? Some Case Study Evidence. http://www.intute.ac.uk/socialsciences/archive/iriss/papers/paper47.htm

Hasanzadeh, R., Beydokhti, A., \& Zadeh, F. D. (2012). The Prevalence of Internet Addiction among University Students: A General or Specific Problem? Journal of Basic and Applied Scientific Research, 2, 5264-5271.

Hetherington, E. M. (2011). Adolescent Autonomy with Parents as a Predictor of Low Susceptibility to Peer Pressure. www.people.virginia.edu/ psykliff/pubs/publications/charlotte\%20geary.pdf

Itliong, M. S. (2006). The Constructs of Spiritual Intelligence, It's Correlates with Stress Management and Variation across Selected Variables. Unpublished Master's Thesis, Baguio City: Saint Louis University.

Johnson, T. P., \& Fendrich, M. (2013). A Validation of the Crowne-Marlowe Social Desirability Scale. www.srl.uic.edu/publist/Conference/crownemarlowe.pdf

Kennedy, T., Wellman, B., \& Klement, K. (2003). Gendering the Digital Divide. IT \& Society, 1, 72-96.

King, D. B., \& DeCicco, T. L. (2008). A Viable Model and Self-Report Measure of Spiritual Intelligence. The International Journal of Transpersonal Studies, 28, 68-85.

Ko, C. H., Yen, J. Y., Chen, C. C., Chen, S. H., \& Yen, C. F. (2005). Proposed Diagnostic Criteria of Internet Addiction for Adolescents. The Journal of Nervous \& Mental Disease, 193, 728-733. http://dx.doi.org/10.1097/01.nmd.0000185891.13719.54

Ko, C. H., Yen, J. Y., Yen, C. F., Chen, C. S., \& Chen, C. C. (2012). The Association between Internet Addiction and Psychiatric Disorder: A Review of the Literature. European Psychiatry, 27, 1-8.

Mannell, R. C., Zuzanek, J., \& Aronson, R. (2013). Internet/Computer Use and Adolescent Leisure Behavior, Flow Experiences and Psychological Well-Being: The Displacement Hypothesis. www.lin.ca/sites/default/files/attachments/CCLR11-89.pdf

Mazalin, D., \& Moore, S. (2004). Internet Use, Identity Development and Social Anxiety among Young Adults. http://download.9nature.com./internet-use-identity-development-and-social-anxiety-download-w2054/

Negovan, V. (2010). Dimensions of Students’ Psychosocial Well-Being and Their Measurement: Validation of a Students' 
Psychosocial Well Being Inventory. Europe’s Journal of Psychology, 6, 85-104.

Oktuğ, Z. (2010). Gender Differences in Internet Addiction and Tendency to Express Emotions. Cyberpsychology: Journal of Psychosocial Research on Cyberspace, 1, 39-53.

Perez, J. A. (2012). International Journal of Humanities and Social Science Vol. 2, No. 13. (U. C Centre for Promoting Ideas, Ed.). www.ijhssnet.com

Pudrovska, T., Springer, K. W., \& Hauser, R. M. (2005). Does Psychological Well-Being Change with Age? Longitudinal Tests of Age Variations and Further Exploration of the Multidimensionality of Ryff's Model of Psychological Well-Being. Social Science Research, 40, 392-398. http://dx.doi.org/10.1016/j.ssresearch.2010.05.008

Pui, M. S. (2006). Prediction of Internet Addiction for Undergraduates in Hong Kong. Unpublished Bachelors of Business Administration (Honours) Thesis, Kowloon, Hong Kong: Hong Kong Baptist University.

Qin, Y. S. (2011). A Study of Internet Addiction among Students of Sekolah Menengah Jenis Kebangsaan Pei Yuan, Kampar. www.readbag.com/eprints-utar-my-274-1-py-2011-0802518

Rahmani, S., \& Lavasani, M. (2011). The Relationship between Internet Dependency with Sensation Seeking and Personality. Procedia-Social and Behavioral Sciences, 30, 272-277. http://dx.doi.org/10.1016/j.sbspro.2011.10.054

Razieh, J., Ghasempoor, A., Ajdari, Z., \& Sadeghigooghari, N. (2012). The Relationship between Internet Addiction and Anxiety in the Universities Students. Interdisciplinary Journal of Contemporary Research in Business, 4, $942-949$.

Sato, T. (2009). Internet Addiction among Students: Prevalence and Psychological Problems in Japan. www.med.or.jp/english/pdf/2006_07+/279_283.pdf

Sisk, D. (2008). Spiritual Intelligence: The Tenth Intelligence that Integrates All Other Intelligences. www.dept.lamar,edu/connchair/QuickLinks/articles\%202000-2003/SPIRITUAL

Springer, K. W., \& Hauser, R. M. (2011). An Assessment of the Construct Validity of Ryff's Scales of Psychological Wellbeing: Method, Mode and Measurement Effects. Madison, WI: University of Wisconsin-Madison, Department of Sociology and Center for Demography of Health and Aging.

Tatman, A. P., Swogger, M. T., Love, K., \& Cook, M. D. (2013). Psychometric Properties of the Marlowe-Crowne Social Desirability Scale with Adult Male Sexual Offenders. Iowa, Sexual Abuse, 21, 21-34. http://dx.doi.org/10.1177/1079063208325203

Wang, X. (Date Unknown). The Philippines: The Pacific Bridge across Cultures. http://www.ncl.ac.uk/.../documents/pdf/countryfiles/CCC-Philippines.pdf

Whang, L., Lee, H., \& Chang, G. (2003). Internet Over-Users’ Psychological Profiles: A Behavior Sampling Analysis on Internet Addiction. http://www.encognitive.com/files/Internet\%20Over-Users'\%20Psychological...

Xu, J., Shen, L. X., Yan, C. H., Hu, H., Yang, F., Wang, L. et al. (2012). Personal Characteristics Related to the Risk of Adolescent Internet Addiction: A Survey in Shanghai, China. http://www.biomedcentral.com/1471-2458/12/1106

Young, K. S. (1996). Internet Addiction: The Emergence of a New Clinical Disorder. CyberPsychology \& Behavior, 1, 237-244. http://www.netaddiction.com/articles/newdisorder.pdf http://dx.doi.org/10.1089/cpb.1998.1.237

Young, K. S. (2004). Internet Addiction: A New Clinical Phenomenon and Its Consequences. American Behavioral Scientist, 48, 402-415. http://dx.doi.org/10.1177/0002764204270278

Young, K. S., \& Rogers, R. C. (1998). Internet Addiction: Personality Traits Associated with Its Development. www.netaddiction.com/articles/personality_correlates.pdf 
Scientific Research Publishing (SCIRP) is one of the largest Open Access journal publishers. It is currently publishing more than 200 open access, online, peer-reviewed journals covering a wide range of academic disciplines. SCIRP serves the worldwide academic communities and contributes to the progress and application of science with its publication.

Other selected journals from SCIRP are listed as below. Submit your manuscript to us via either submit@scirp.org or Online Submission Portal.
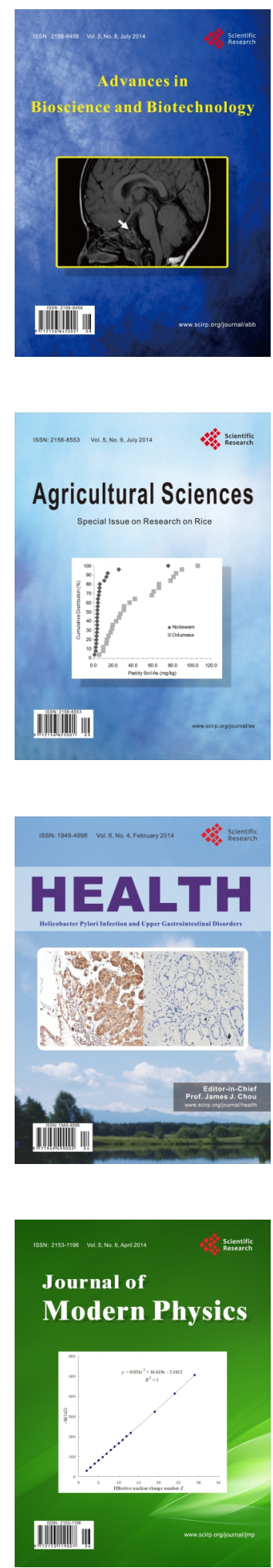
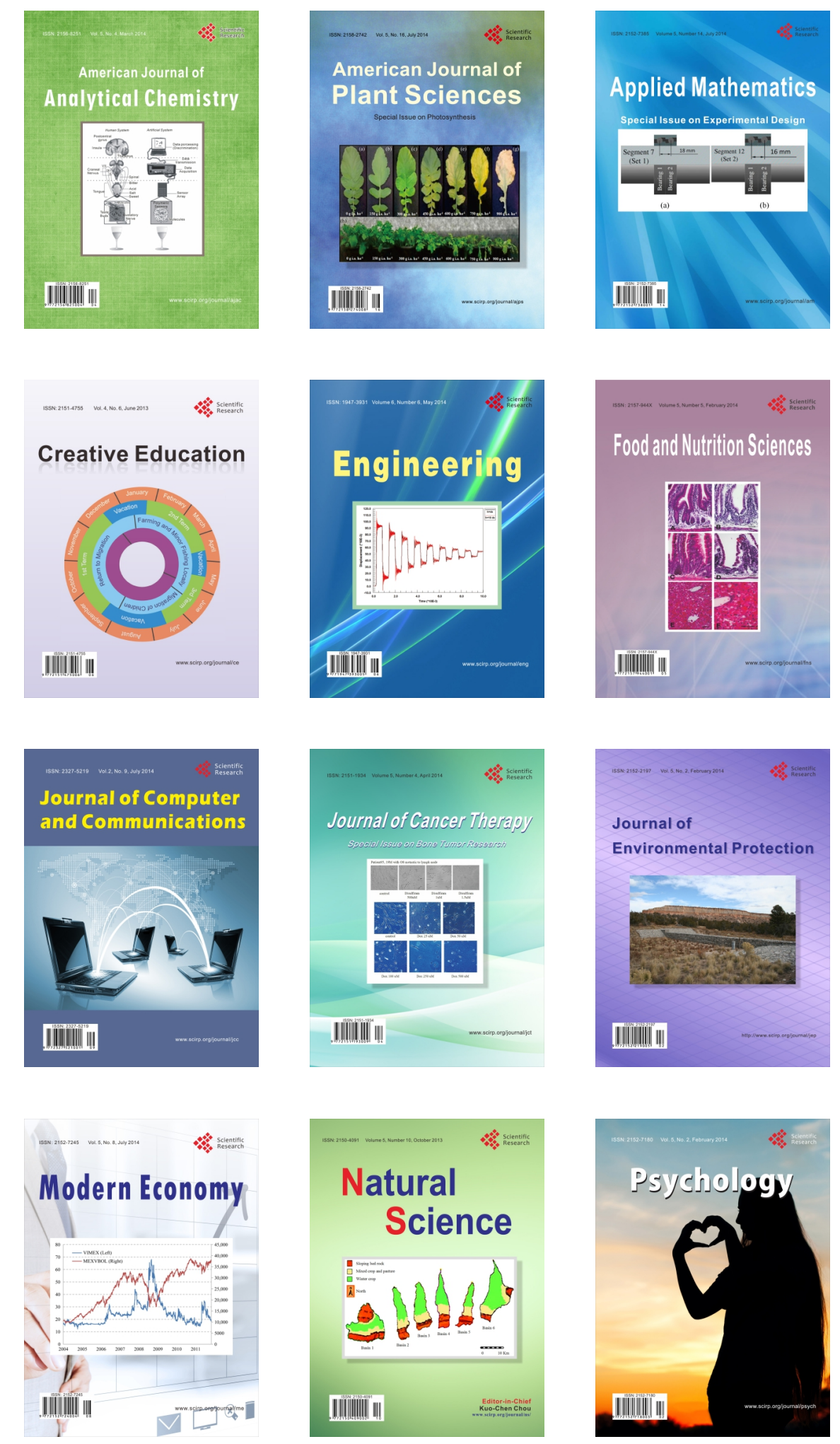